\title{
Theoretical Study of the Chemoselectivity of Tungsten-Dependent Acetylene Hydratase
}

\author{
Rong-Zhen $\mathrm{Liao}^{\dagger}$ and Fahmi Himo* \\ Department of Organic Chemistry, Arrhenius Laboratory, Stockholm University, SE-10691 Stockholm, Sweden \\ Supporting Information
}

ABSTRACT: The tungsten-dependent enzyme acetylene hydratase catalyzes the hydration of acetylene to acetaldehyde. Very recently, we proposed a reaction mechanism for this enzyme based on density functional calculations (Proc. Natl. Acad. Sci. U.S.A. 2010, 107, 22523). The mechanism involves direct coordination of the substrate to the tungsten ion, followed by a nucleophilic attack by a water molecule concerted with a proton transfer to a second-shell aspartate, which then reprotonates the substrate. Here, we use the same methodology

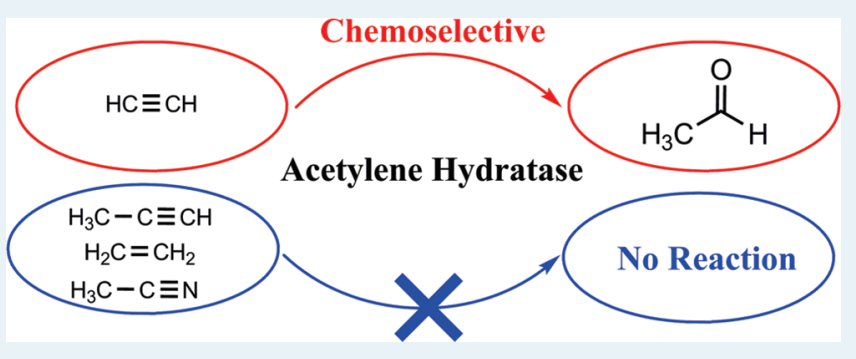
to investigate the factors involved in the control of the chemoselectivity of this enzyme. The hydration reactions of three representative compounds (propyne, ethylene, and acetonitrile) are investigated using a large model of the active site. The energy of substrate binding to the metal ion and the barrier for the following nucleophilic attack are used to rationalize the experimental observations. It is shown that all three compounds have higher barriers for hydration compared with acetylene. In addition, propyne is shown to have a larger binding energy, explaining its behavior as a competitive inhibitor. Taken together, the results provide further corroboration of our suggested mechanism for acetylene hydratase.

KEYWORDS: acetylene hydratase, enzyme mechanism, chemoselectivity, transition state, density functional theory

\section{INTRODUCTION}

Acetylene hydratase $(\mathrm{AH})$ is a tungsten-dependent bacterial enzyme that catalyzes the hydration of acetylene to acetaldehyde. $^{1-3}$ The acetaldehyde product is used by aldehyde dehydrogenase to generate acetyl-coenzyme A, which phosphate acetyltransferase then uses to produce acetylphosphate. This, in turn, reacts with ADP to generate ATP, a reaction catalyzed by acetate kinase. $^{4-6}$ The energy of the last reaction is used for the growth of certain aerobic bacteria. Acetylene thus provides an important source of carbon and energy for these bacteria.

The crystal structure of $\mathrm{AH}$ has been reported and reveals that the tungsten ion in the active site is hexa-coordinated, with the first-shell coordination consisting of two pterin cofactors, a cysteine residue (Cys141), and a water molecule. ${ }^{7}$ An important second-shell residue, Asp13, forms a hydrogen bond to the tungsten-bound water molecule. $\mathrm{W}^{\mathrm{IV}}$ has been demonstrated to be the reactive form, whereas $\mathrm{W}^{\mathrm{VI}}$ is inactive. ${ }^{3,8}$

Very recently, we used quantum chemical calculations to investigate the reaction mechanism of this enzyme. ${ }^{9}$ A quite large model of the active site was designed, and the B3LYP hybrid density functional theory method ${ }^{10,11}$ was used to calculate the potential energy profiles for several possible mechanistic scenarios. On the basis of the calculations, a new first-shell mechanism was suggested, as shown in Scheme 1. In this mechanism, the acetylene substrate first displaces the tungsten-bound water molecule. This is followed by a nucleophilic attack on acetylene by the water molecule, facilitated by the ionized second-shell
Asp13 residue, which concertedly with the nucleophilic attack abstracts a proton from the water molecule. In the next step, Asp13 delivers the proton back to the vinyl anion intermediate, affording vinyl alcohol. Finally, the isomerization to acetaldehyde takes place with the assistance of Asp13. Asp13 is thus crucial for the activity of the enzyme, a fact confirmed by recent mutational studies. ${ }^{12}$ Other suggested mechanisms have been shown to have high energy barriers. These include a second-shell electrophilic addition mechanism; ${ }^{7}$ a first-shell one-step mechanism involving water nucleophilic attack on acetylene, facilitated by a neutral Asp 13 residue; ${ }^{13}$ and a first-shell mechanism proceeding through a $\mathrm{W}=\mathrm{C}=\mathrm{CH}_{2}$ vinylidene intermediate. ${ }^{14}$ Interestingly, a reaction mechanism similar to the one of Scheme 1 has also been proposed for acetylene hydration catalyzed by a biomimetic tungsten complex. ${ }^{15}$ It is suggested that a tungsten-bound hydroxide plays the key role performed by Asp13 in the enzyme.

Somewhat peculiarly, it has been found experimentally that $\mathrm{AH}$ is not able to hydrate substituted alkynes, such as propyne, $p$-toluylacetylene, acetylene monocarboxylate, and acetylene dicarboxylate. Instead, these compounds were found to be competitive inhibitors. ${ }^{2}$ Similar observations were made for the smaller compounds carbon monoxide and cyanide. ${ }^{2}$ In addition, $\mathrm{AH}$ has been shown to have no activity toward ethylene or

Received: May 10, 2011

Revised: June 23, 2011

Published: July 05, 2011 
Scheme 1. Reaction Mechanism of AH Suggested on the Basis of Previous Calculations ${ }^{9}$
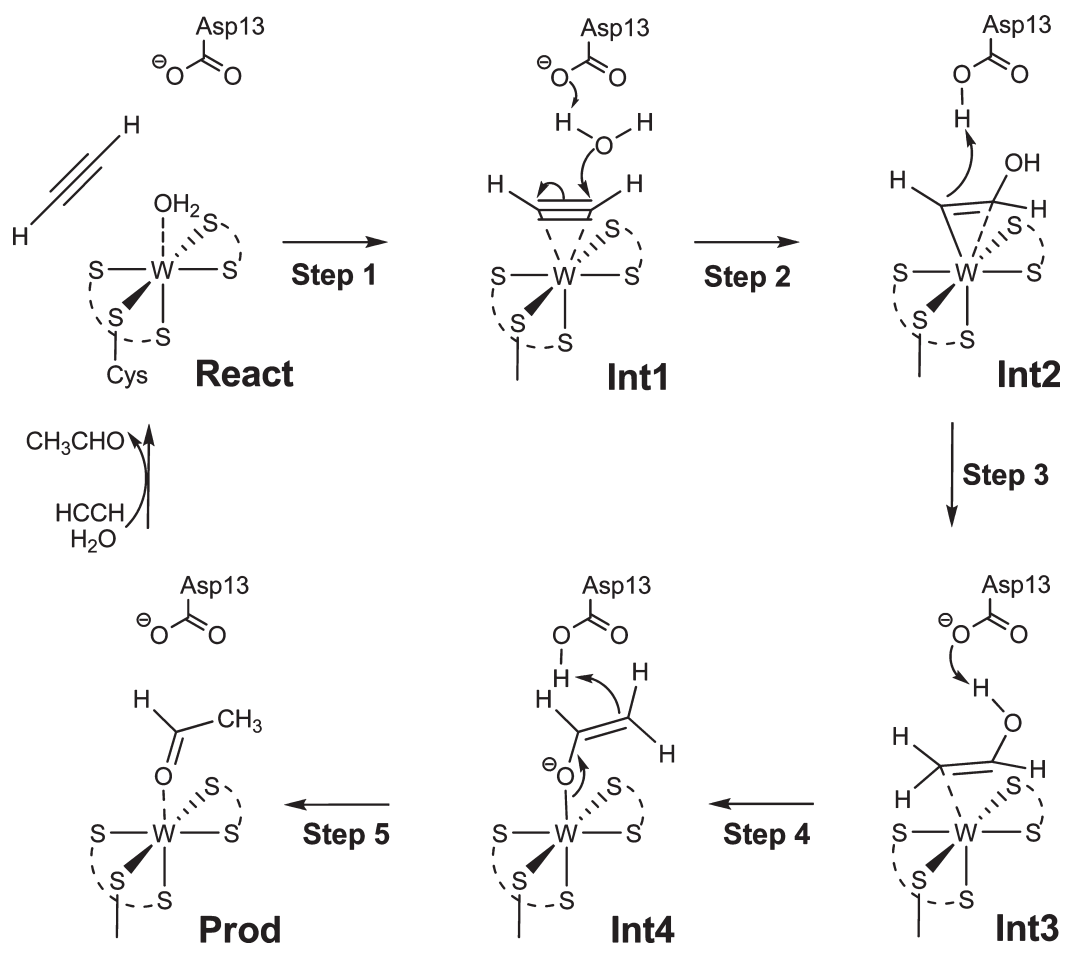

nitriles. ${ }^{3}$ It is not known whether these compounds at all bind to the tungsten ion.

To rationalize these observations and to examine whether they can be explained within the framework of the proposed reaction mechanism of AH (Scheme 1), we have in the present study used the same quantum chemical cluster approach adopted in our previous investigation. ${ }^{9}$ Three representative substrates were chosen-namely, propyne, ethylene, and acetonitrile-and the energies involved in their binding and hydration reactions at the $\mathrm{AH}$ active site were calculated.

\section{COMPUTATIONAL DETAILS}

The calculations presented here were performed using the same methods as in the previous study on the $\mathrm{AH}$ mechanism. ${ }^{9}$ All calculations were performed using the Gaussian03 program package ${ }^{16}$ with the B3LYP functional. ${ }^{10,11}$ Geometries were optimized with the LANL2TZ $(\mathrm{f}){ }^{17}$ pseudopotential for $\mathrm{W} ; 6-311+\mathrm{G}(\mathrm{d})$ for $\mathrm{S}$; and 6-31G $(d, p)$ for $C, N, O$, and $H$. Energies were then obtained from single-point calculations on the optimized structures using the larger basis set $6-311+G(2 d, 2 p)$ for all elements except $W$, for which the LANL2TZ(f) basis set was used. The singlet state was considered for all stationary points, since the triplet state lies $\sim 20 \mathrm{kcal} / \mathrm{mol}$ higher. Solvation effects from the missing protein surrounding were evaluated by performing single-point calculations on the optimized structures using the conductor-like polarizable continuum model ${ }^{18-21}$ at the same level of theory as the geometry optimizations. The dielectric constant was set equal to 4, in line with previous modeling of enzymes. Hessians were calculated to obtain the zero-point energies (ZPE). The procedure of keeping a number of atoms fixed in the geometry optimizations (see below), gives rise to several small imaginary frequencies, in this case on the order of $10 i-40 i \mathrm{~cm}^{-1}$. These contribute insignificantly to the ZPE and can

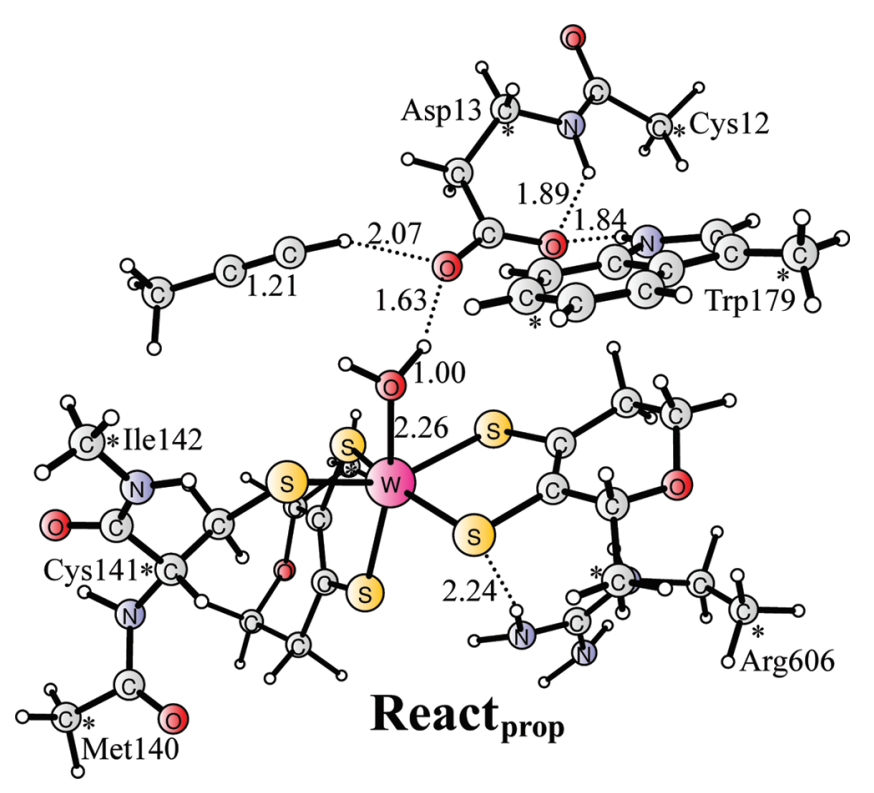

Figure 1. Optimized structure of the active site model of AH in complex with propyne ( React $_{\text {prop }}$ ). Atoms marked with asterisks were fixed at their X-ray structure positions during the geometry optimizations. Distances are given in angstroms $(\AA)$.

thus be disregarded. The final energies reported below include both solvation effects and ZPE effects.

\section{ACTIVE SITE MODEL}

The active site model used to study the reactions of $\mathrm{AH}$ with propyne, ethylene, and acetonitrile is the same as the one used 

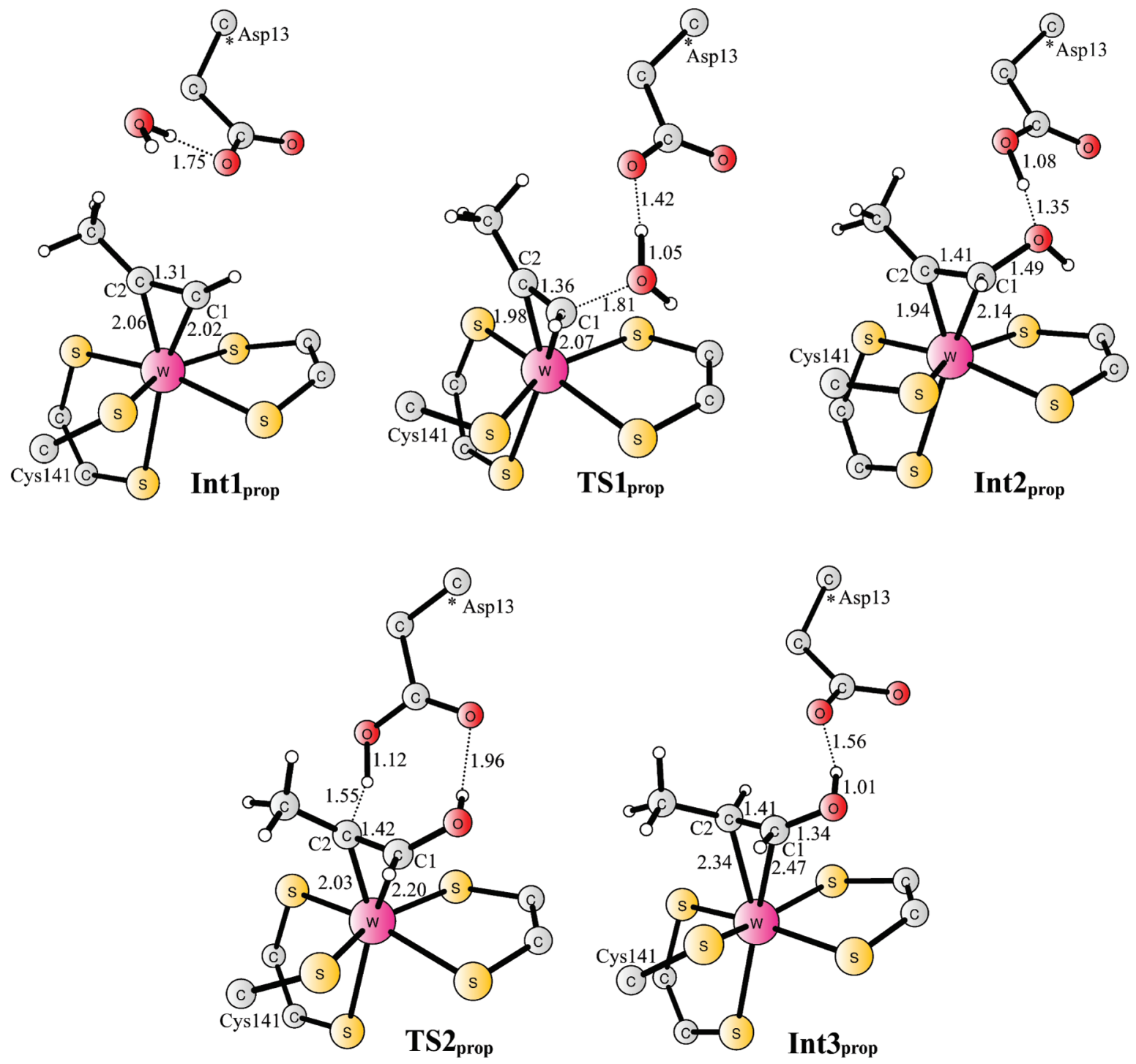

Figure 2. Optimized structures of the intermediates and transition states along the reaction pathway for propyne hydration. For clarity, only the central part of the model is shown. See Figure 1 for the full model.

previously to study the reaction of acetylene. ${ }^{9}$ It is based on the crystal structure of native $\mathrm{AH}(\mathrm{PDB} \text { entry } 2 \mathrm{E} 7 \mathrm{Z})^{7}$ and consists of the tungsten ion along with models of its first-shell ligands, including the two pterin molecules, the Met140-Cys141-Ile142 peptide, and a water molecule as well as a number of potentially important second-shell residues: Cys12, Asp13, Trp179, and Arg606. The pterin molecules and the amino acid residues were truncated so that in principle only the functional groups were kept in the model, as shown in Figure 1. Hydrogen atoms were added manually. Following the results of our previous study, Asp13 was modeled in the ionized form. To maintain the overall structure of the active site and prevent the various groups from making artificial movements not allowed in the enzyme environment, the truncated atoms were fixed to their corresponding positions from the X-ray structure during the geometry optimizations. This is a standard procedure used in the cluster approach for modeling enzyme active sites and reaction mechanisms. ${ }^{22-25}$ The fixed atoms are marked with asterisks in figures below. The total sizes of the model in complex with propyne, ethylene, and acetonitrile, are 119,118 , and 118 atoms, respectively, and the overall charge is -1 for all models.

\section{RESULTS AND DISCUSSION}

Before discussing the new results regarding the reactions of propyne, ethylene, and acetonitrile, it is useful to summarize the main findings on the mechanism of acetylene hydration shown in Scheme 1. ${ }^{9}$ The first step (React $\rightarrow$ Int 1 ) is a ligand exchange in which the substrate displaces the tungsten-bound water molecule and binds to the metal in an $\eta^{2}$ fashion. The step was calculated to be exothermic by $5.4 \mathrm{kcal} / \mathrm{mol}$. Next, the displaced water molecule performs a nucleophilic attack on the acetylene concertedly with a proton transfer to Asp13 to yield the vinyl anion intermediate Int2. The barrier for this step was calculated to be $16.9 \mathrm{kcal} / \mathrm{mol}$ relative to Int 1 . The following step (Int2 $\rightarrow$ Int3) was found to be rate-limiting and involves a proton transfer from Asp13 back to the carbon of the substrate to give vinyl alcohol. The overall barrier, that is, relative to Int1, was calculated to be 


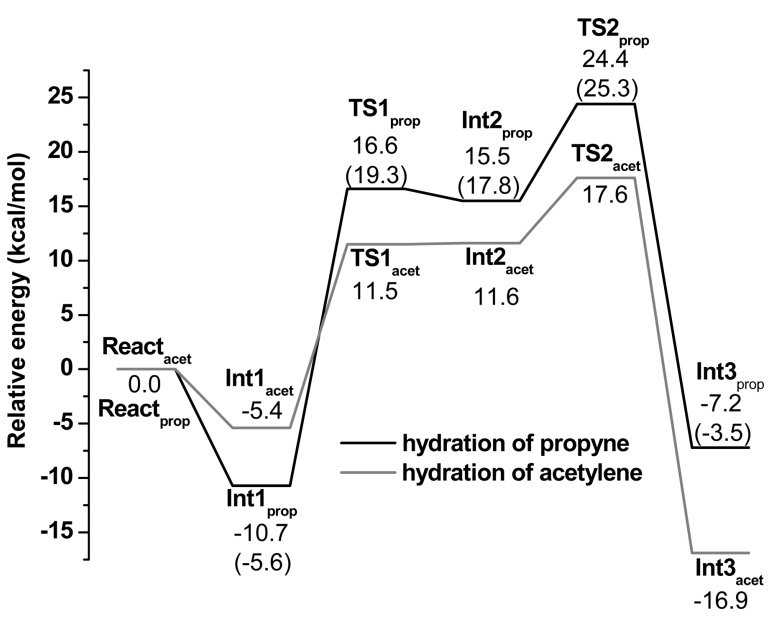

Figure 3. Calculated potential energy profile for propyne hydration. The previously calculated energy profile for acetylene hydration is also shown for comparison. Values in parentheses are without solvation correction.

$23.0 \mathrm{kcal} / \mathrm{mol}$, and Int 3 was calculated to be $11.5 \mathrm{kcal} / \mathrm{mol}$ more stable than Int1. The two following steps involve a tautomerization of the vinyl alcohol to acetaldehyde and were found to have quite low barriers. ${ }^{9}$

It is also useful to briefly discuss the molecular orbital (MO) interactions between the substrate and the metal at Int1 (a detailed MO interaction diagram is given in the Supporting Information). Acetylene is a $4 \mathrm{e}$ donor with its two $\pi$ orbitals interacting with two empty $\mathrm{d}$ orbitals of the tungsten. The occupied $\mathrm{d}$ orbital of $\mathrm{W}^{\mathrm{IV}}$ back-donates two electrons to one of two unoccupied $\pi^{*}$ orbitals of acetylene. One of the remaining unoccupied d orbitals of tungsten interacts with the other unoccupied $\pi^{*}$ orbital of acetylene to form a $\delta$-like orbital, which can facilitate the electron transfer to this empty molecular orbital during the nucleophilic attack on the acetylene. This MO analysis shows that the $\mathrm{d}^{2}$-configuration of the metal is required to bind and weaken the triple bond and also to facilitate the nucleophilic attack, which was suggested to explain why only $\mathrm{W}^{\mathrm{IV}}$ and $\mathrm{Mo}^{\mathrm{IV}}$ can be used in enzymatic acetylene activation. ${ }^{9}$

In what follows, the reactions of each of propyne, ethylene, and acetonitrile at the active site model are discussed, and the energy profiles are compared with the acetylene reaction.

IV.A. Hydration of Propyne. The optimized structures of the stationary points for the hydration of propyne at the $\mathrm{AH}$ active site are shown in Figures 1 and 2, and the associated potential energy profile is given in Figure 3. The energies of acetylene hydration are also given in the figure for comparison.

Geometrically, propyne binds to tungsten in a similar way as acetylene. The ligand exchange energy, however, is quite different. The calculations show that the first step now is exothermic by $10.7 \mathrm{kcal} / \mathrm{mol}$, that is, $5.3 \mathrm{kcal} / \mathrm{mol}$ more than for acetylene. The electron-donating character of the methyl substitutent raises the HOMO energy by $0.6 \mathrm{eV}$ (energies of the frontier orbitals of the three substrates under investigation are compared with those of acetylene in the Supporting Information) and makes the $\pi$ donation to the two empty $d$ orbitals of tungsten better, thereof the greater binding energy.

From Int $1_{\text {prop}}$, the barrier of the following nucleophilic attack was calculated to be $27.3 \mathrm{kcal} / \mathrm{mol}$, which is more than $10 \mathrm{kcal} /$ mol higher than for acetylene. The LUMO of propyne is $0.3 \mathrm{eV}$ higher than that of acetylene, and the electron transfer to the $\pi^{*}$ orbital taking place during the nucleophilic attack will be worse. In addition, the anion formed at the $\mathrm{C} 2$ position is less stable with the methyl substituent. Another possible reason for the difference between acetylene and propyne is the steric repulsion between the methyl substituent and the pterin ligand (Figure 2).

The rate-limiting proton transfer step from Asp13 residue to the $\mathrm{C} 2$ center of the vinyl anion has an overall barrier of $35.1 \mathrm{kcal} / \mathrm{mol}$ relative to Int $_{\text {prop }}$, which is $\sim 12 \mathrm{kcal} / \mathrm{mol}$ higher than that of acetylene, and the step is exothermic by $22.7 \mathrm{kcal} /$ mol, which is $\sim 6 \mathrm{kcal} / \mathrm{mol}$ less than that of acetylene. 9

The calculations thus show that propyne binds to the tungsten better than acetylene, and the barriers for the nucleophilic attack and the following protonation of the carbon are much higher. These two facts explain why propyne acts as a competitive inhibitor of $\mathrm{AH}$. The same conclusions could be extended to other electron-donating substitutents on the acetylene.

It should be added that the tautomerization steps to yield the final product were not studied for propyne because they are irrelevant, considering the high barriers obtained for the first steps.

IV.B. Hydration of Ethylene. The reactivities of ethylene and acetylene have been demonstrated to be quite similar in many different types of reactions. ${ }^{26-30}$ Quantum chemical calculations have been used to compare the relative reactivities in, for example, cycloaddition, ${ }^{31,32}$ phosphinidene addition, ${ }^{33}$ sulfur addition, ${ }^{34}$ borohydride cation addition, ${ }^{35}$ hydration on zeolite, ${ }^{36}$ and ylidic radical addition. ${ }^{37}$ The barriers for these reactions were found to be rather close between ethylene and acetylene, with the largest difference on the order of $4 \mathrm{kcal} / \mathrm{mol}$.

As mentioned in the Introduction, $\mathrm{AH}$ effects the chemoselective hydration of acetylene in the presence of ethylene. ${ }^{2,3}$ Here, we calculate the energy profile for ethylene hydration to investigate whether this observation can be rationalized within the proposed mechanism. The optimized structures are shown in Figure 4, and the potential energy profile is given in Figure 5.

In contrast to acetylene and propyne, the initial ligand exchange step in the case of ethylene ( React $_{\text {ethy }} \rightarrow$ Int $_{\text {ethy }}$ ) is calculated to be slightly endothermic $(+0.7 \mathrm{kcal} / \mathrm{mol})$. Ethylene, being a $2 \mathrm{e}$ donor with its $\pi$ orbital interacting with one empty $\mathrm{d}$ orbital of tungsten, thus binds weaker than acetylene, which is a $4 \mathrm{e}$ donor (see MO interaction diagrams in the Supporting Information). In addition, the occupied d orbital of tungsten back-donates two electrons to the unoccupied $\pi^{*}$ orbital of ethylene, resulting in an even higher $\pi^{*}$-like orbital (combination of $\pi^{*}$ - orbital and $d$ orbital), which should make the following nucleophilic attack in the next step less favorable.

The optimized transition state structure for the nucleophilic attack $\left(\mathbf{T S}_{\text {ethy }}\right)$ is shown in Figure 4. Indeed, the barrier for the nucleophilic attack is calculated to be $30.0 \mathrm{kcal} / \mathrm{mol}$ relative to Int $1_{\text {ethy }}\left(30.7 \mathrm{kcal} / \mathrm{mol}\right.$ relative to React $\left._{\text {ethy }}\right)$. In the hydration of acetylene, the nucleophilic attack is directed perpendicularly to the $\mathrm{W}-\mathrm{C}-\mathrm{C}$ plane. ${ }^{9}$ In the case of ethylene, a perpendicular attack is impossible, and the only option left for the attack is from the top of the ethylene plane, which is similar to the anti addition in the Pd-catalyzed Wacker process. ${ }^{38-42}$ At TS $_{\text {ethy, }}$ the nascent $\mathrm{C} 1-\mathrm{O}$ bond is $1.83 \AA$, and $\mathrm{C} 1$ dissociates from tungsten with a distance of $2.85 \AA$. The resulting intermediate (Int $\mathbf{2}_{\text {ethy }}$ ) lies at $+22.5 \mathrm{kcal} / \mathrm{mol}$ relative to React $_{\text {ethy }}$. It should be noted that the syn addition in which both the ethylene and the nucleophile coordinate to the metal, as the alternative pathway suggested for $\mathrm{Pd}(\mathrm{II})$ in the Wacker process, ${ }^{40-42}$ is impossible in $\mathrm{AH}$ because 

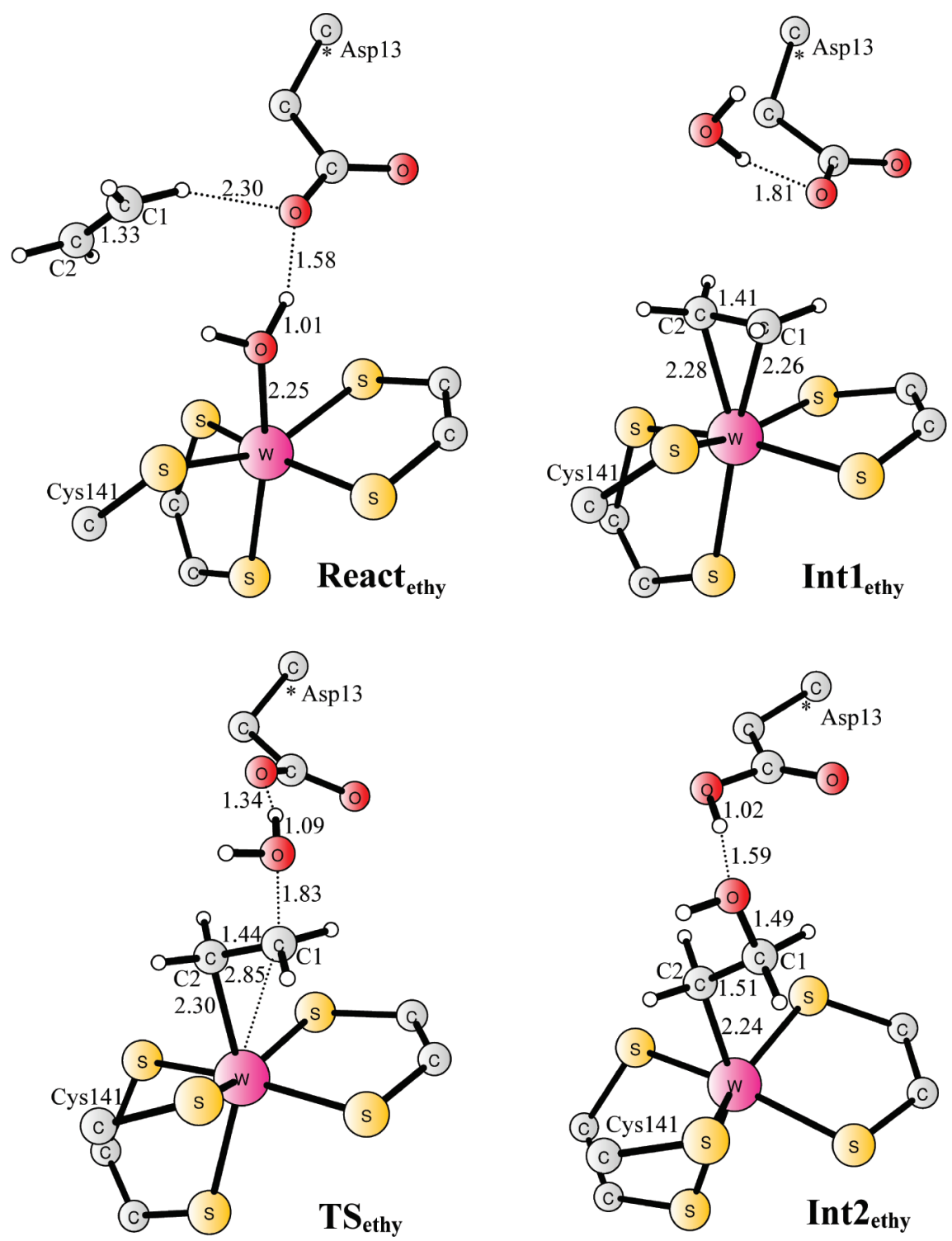

Figure 4. Optimized structures of the reactant, intermediates, and transition state along the reaction pathway for ethylene hydration. For clarity, only the central part of the model is shown. For the full model, see Figure 1.

the hexa-coordinated tungsten cannot accommodate both ethylene and water at the same time.

The calculations thus demonstrate that formation of a tungsten-ethylene complex is energetically less favorable compared with tungsten-acetylene, and most importantly, the subsequent nucleophilic attack step is associated with a high barrier. Taken together, these results explain why hydration of ethylene cannot take place at the $\mathrm{AH}$ active site.

IV.C. Hydration of Acetonitrile. In some bacteria, the conversion of nitriles to their corresponding amides is catalyzed by nitrile hydratases, which require low-spin $\mathrm{Fe}$ (III) or $\mathrm{Co}$ (III) for their activity. ${ }^{43}$ Recent quantum chemical model calculations have shown that the most likely mechanism involves a direct endon coordination of the nitrile to the metal ion. ${ }^{44-46}$ An oxygenated cysteine ligand $\left(\mathrm{Cys} 141-\mathrm{SO}^{-}\right.$) was suggested to abstract a proton from the nucleophilic water molecule to facilitate the attack, and the role of the metal is then to stabilize the anionic imidate intermediate, thereby lowering the barrier. ${ }^{44}$
This mechanism has similarities to the proposed mechanism of Scheme 1 for acetylene hydration, with the ionized Asp13 being the catalytic base, which might indicate that nitriles also are activated by $\mathrm{AH}$. However, it has been experimentally demonstrated that this enzyme is inert toward these compounds. ${ }^{3}$ To understand this observation, we calculate here the energies involved in the hydration of acetonitrile at the $\mathrm{AH}$ active site model.

Acetonitrile can bind to tungsten both end-on ( of Figure 6) or side-on (Int $1_{\text {nitr-side-on }}$ of Figure 7), as has been observed in a number of Mo- and W-nitrile complexes. ${ }^{47-49}$ For both binding modes, the initial ligand exchange step is calculated to be quite endothermic, $7.8 \mathrm{kcal} / \mathrm{mol}$ for end-on and $9.3 \mathrm{kcal} / \mathrm{mol}$ for side-on.

From Int $1_{\text {nitr-end-on }}$ Asp13 activates the water molecule to perform the nucleophilic attack on nitrile $\mathrm{C} 1$ via $\mathbf{T S} \mathbf{1}_{\text {nitr-end-on }}$ to form an imidate intermediate Int $\boldsymbol{2}_{\text {nitr-end-on. The barrier is }}$ calculated to be $16.5 \mathrm{kcal} / \mathrm{mol}$ relative to $\mathbf{I n t} \mathbf{1}_{\text {nitr-end-on, that is, }}$ 
$25.8 \mathrm{kcal} / \mathrm{mol}$ relative to React $_{\text {nitr. }}$ The barrier is $2.8 \mathrm{kcal} / \mathrm{mol}$ higher than that of acetylene hydration. ${ }^{9}$ At $\mathbf{T S} 1_{\text {nitr-end-on, the }}$ $\mathrm{O}-\mathrm{C} 1$ distance is $1.75 \AA$, and the water proton is located at a distance of $1.10 \AA$ from the water oxygen and $1.32 \AA$ from the Asp13 carboxylate oxygen. During the attack, the $\mathrm{W}-\mathrm{N}$ bond

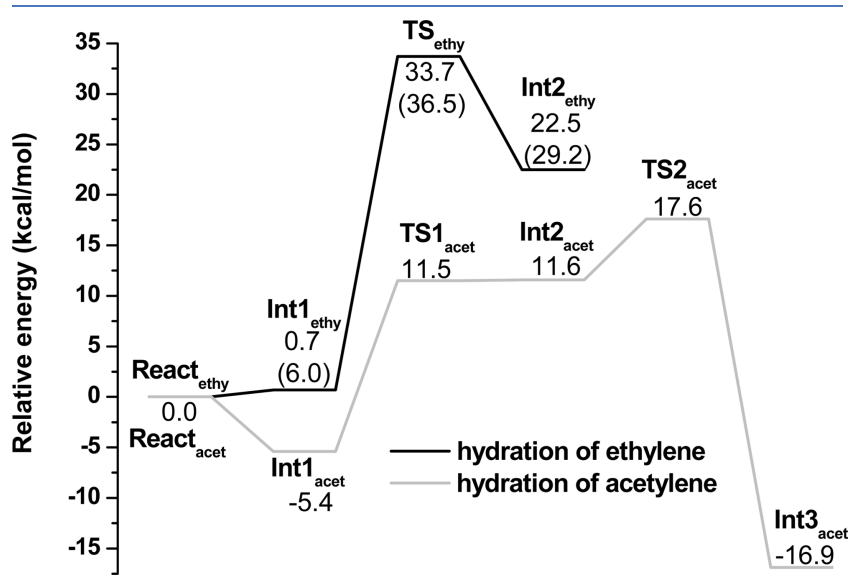

Figure 5. Calculated potential energy profile for ethylene hydration. Values in parentheses are without solvation correction. length decreases from $2.14 \AA$ in $\operatorname{Int} 1_{\text {nitr-end-on }}$ to $1.91 \AA$

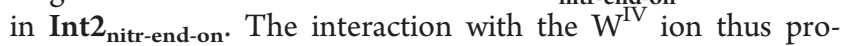
vides electrostatic stabilization on the negative charge of the intermediate.

A very fast proton transfer from Asp13 to the imidate intermediate takes place after its formation, leading to a neutral intermediate Int $3_{\text {nitr-end-on }}$ which is $3.0 \mathrm{kcal} / \mathrm{mol}$ lower than React $_{\text {nitr. }}$. Further isomerization to acetamide can easily occur in solution, as demonstrated by previous theoretical calculations. ${ }^{44}$ The rate-limiting step in the hydration of acetonitrile is thus the nucleophilic attack (see potential energy graph in Figure 8), which is consistent with the findings for nitrile hydratase ${ }^{44}$ but in contrast to acetylene hydration, for which the following proton transfer was found to be rate-limiting (see above).

For the alternative side-on binding mode, the optimized transition state for the nucleophilic attack and the resulting intermediate are shown in Figure 7. This pathway is calculated to have a much higher barrier $(34.8 \mathrm{kcal} / \mathrm{mol})$, which rules out this possibility.

The overall barrier of acetonitrile hydration is thus calculated to be $2.8 \mathrm{kcal} / \mathrm{mol}$ higher than acetylene hydration. Although this energy difference is too small to draw firm conclusions about the reactivity, it is in the right direction, which is consistent with the experimental observation.
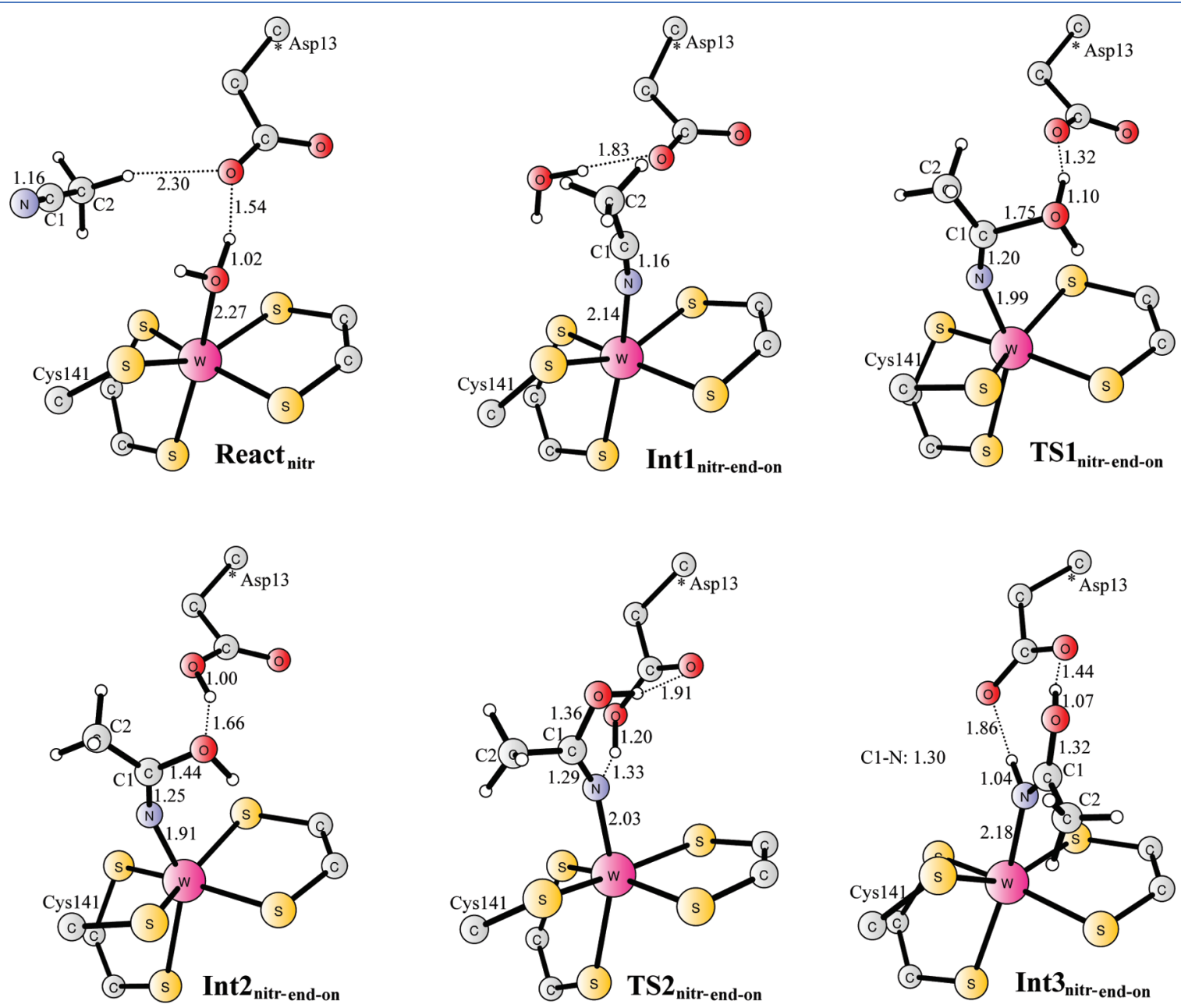

Figure 6. Optimized structures of the reactant, intermediates and transition states along the reaction pathway for acetonitrile hydration in end-on substrate binding. For clarity, only the central part of the model is shown. For full model, see Figure 1. 

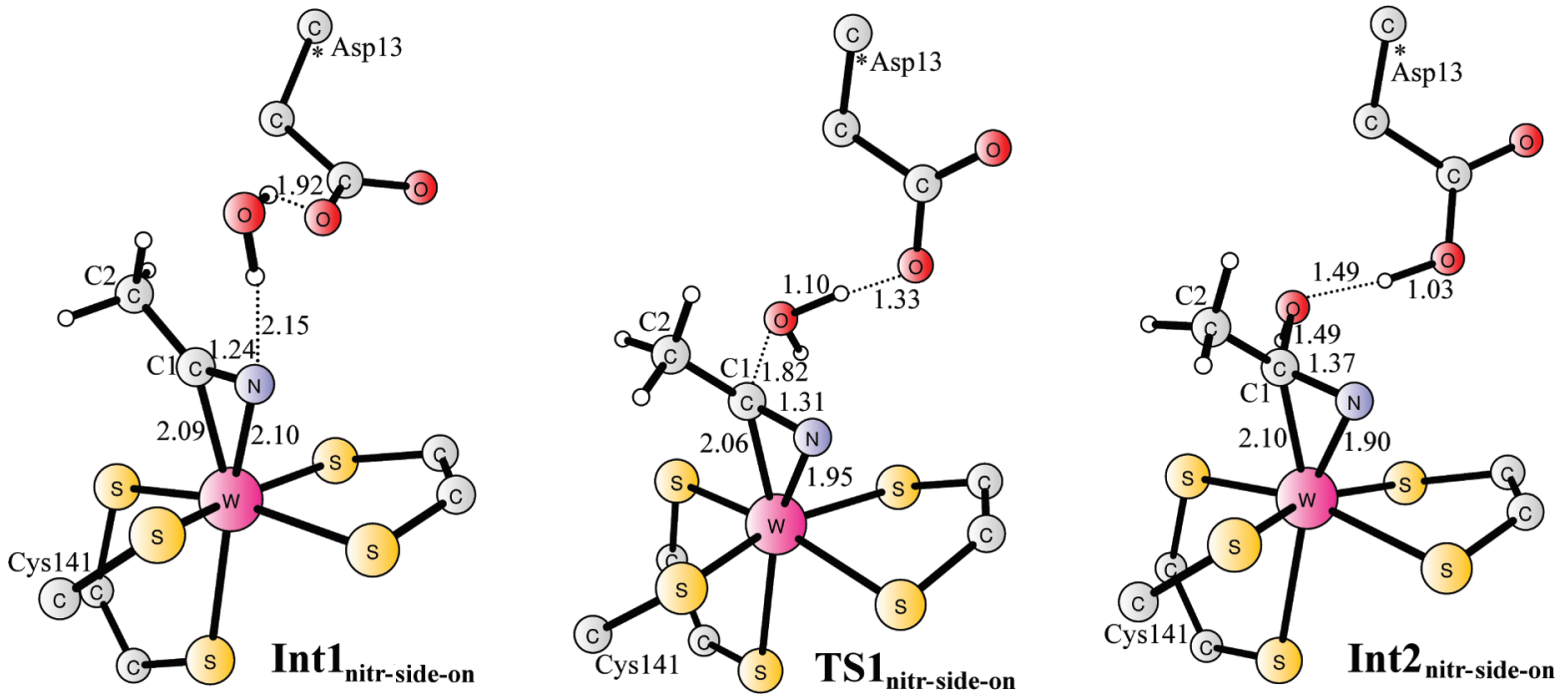

Figure 7. Optimized structures of the intermediates and transition state along the reaction pathway for acetonitrile hydration in side-on substrate binding. For clarity, only the central part of the model is shown. For full model, see Figure 1.

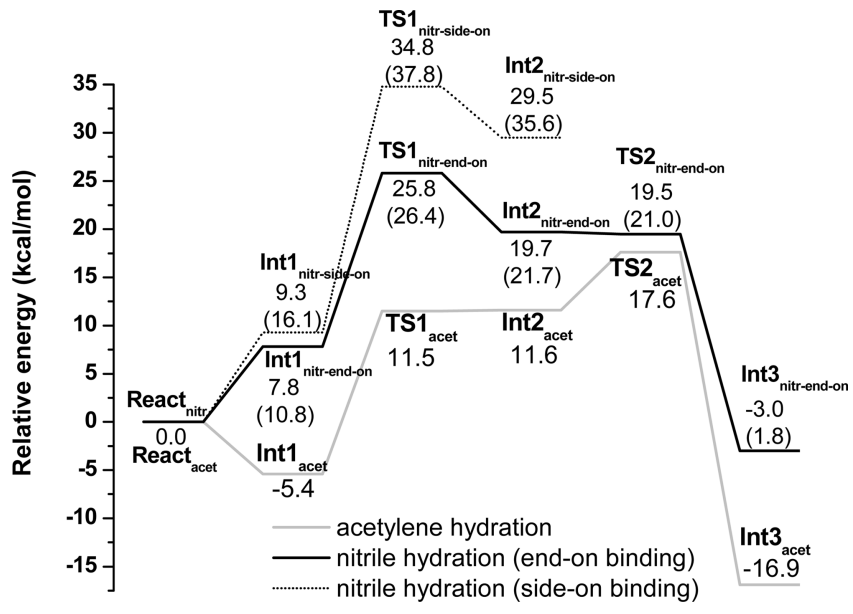

Figure 8. Calculated potential energy profile for acetonitrile hydration. Values in parentheses are without solvation correction.

\section{CONCLUSIONS}

In the present paper, density functional calculations were performed to study the reactions of propyne, ethylene, and acetonitrile with acetylene hydratase. For all three compounds, the calculated barriers are higher than that for the natural substrate acetylene. For propyne, the binding energy to the tungsten is shown to be $\sim 5 \mathrm{kcal} / \mathrm{mol}$ more than that of acetylene, and the following steps have an overall barrier of $\sim 35 \mathrm{kcal} / \mathrm{mol}$. These two facts explain why propyne acts as a competitive inhibitor of $\mathrm{AH}$.

The binding of ethylene to tungsten, on the other hand, is shown to be $\sim 6 \mathrm{kcal} / \mathrm{mol}$ worse than acetylene. The following nucleophilic attack is calculated to have a very high barrier, showing thus that ethylene cannot be a substrate of $\mathrm{AH}$.

For acetonitrile, the calculations show that the binding to the metal is as much as $13 \mathrm{kcal} / \mathrm{mol}$ worse than acetylene, but the overall barrier for hydration is only $\sim 3 \mathrm{kcal} / \mathrm{mol}$ higher. The trend is thus consistent with the experimental observation that nitriles are not substrates of $\mathrm{AH}$, but the obtained energy difference is not sufficient to draw firm conclusions about these substrates.

Finally, it is important to point out that the fact that the calculations reproduce the experimental observations provides further support to our previously suggested mechanism.

\section{ASSOCIATED CONTENT}

S Supporting Information. Orbital interaction diagrams for substrate-metal binding, calculated frontier orbital energies for the studied substrates, and Cartesian coordinates of all optimized structures. This material is available free of charge via the Internet at http://pubs.acs.org.

\section{AUTHOR INFORMATION}

\section{Corresponding Author}

*E-mail: himo@organ.su.se.

\section{Present Addresses}

${ }^{\dagger}$ Max-Planck-Institut für Kohlenforschung, Kaiser-Wilhelm-Platz 1, D-45470, Mülheim an der Ruhr, Germany.

\section{ACKNOWLEDGMENT}

We acknowledge financial support from The Swedish Research Council (Grants 621-2009-4736 and 622-2009-371) and computer time from the PDC Center for High Performance Computing.

\section{REFERENCES}

(1) Schink, B. Arch. Microbiol. 1985, 142, 295-301.

(2) Meckenstock, R. U.; Krieger, R.; Ensign, S.; Kroneck, P. M. H.; Schink, B. Eur. J. Biochem. 1999, 264, 176-182.

(3) Rosner, B. M.; Schink, B. J. Bacteriol. 1995, 177, 5767-5772.

(4) Buschhorn, H.; Dürre, P.; Gottschalk, G. Arch. Microbiol. 1992, $158,132-138$.

(5) Stadtman, E. R. J. Biol. Chem. 1952, 196, 527-534.

(6) Fox, D. K.; Roseman, S. J. Biol. Chem. 1986, 261, 13487-13497. 
(7) Seiffert, G. B.; Ullmann, G. M.; Messerschmidt, A.; Schink, B.; Kroneck, P. M. H.; Einsle, O. Proc. Natl. Acad. Sci. U.S.A. 2007, 104, 3073-3077.

(8) Yadav, J.; Das, S. K.; Sarkar, S. J. Am. Chem. Soc. 1997, 119, 4315-4316.

(9) Liao, R.-Z.; Yu, J.-G.; Himo, F. Proc. Natl. Acad. Sci. U.S.A. 2010, 107, 22523-22527.

(10) Becke, A. D. J. Chem. Phys. 1993, 98, 5648-5652.

(11) Lee, C.; Yang, W.; Parr, R. G. Phys. Rev. B 1988, 37, 785-789.

(12) ten Brink, F.; Schink, B.; Kroneck, P. M. H. J. Bacteriol. 2011, 193, 1229-1236.

(13) Antony, S.; Bayse, C. A. Organometallics 2009, 28, 4938-4944.

(14) Vincent, M. A.; Hillier, I. H.; Periyasamy, G.; Burton, N. A. Dalton Trans. 2010, 39, 3816-3822.

(15) Liu, Y.-F.; Liao, R.-Z.; Ding, W.-J.; Yu, J.-G.; Liu, R.-Z. J. Biol. Inorg. Chem. 2011, 16, 745-752.

(16) Frisch, M. J.; Trucks, G. W.; Schlegel, H. B.; Scuseria, G. E.; Robb, M. A.; Cheeseman, J. R.; Montgomery, J. A., Jr.; Vreven, T.; Kudin, K. N.; Burant, J. C.; Millam, J. M.; Iyengar, S. S.; Tomasi, J.; Barone, V.; Mennucci, B.; Cossi, M.; Scalmani, G.; Rega, N.; Petersson, G. A.; Nakatsuji, H.; Hada, M.; Ehara, M.; Toyota, K.; Fukuda, R.; Hasegawa, J.; Ishida, M.; Nakajima, T.; Honda, Y.; Kitao, O.; Nakai, H.; Klene, M.; Li, X.; Knox, J. E.; Hratchian, H. P.; Cross, J. B.; Bakken, V.; Adamo, C.; Jaramillo, J.; Gomperts, R.; Stratmann, R. E.; Yazyev, O.; Austin, A. J.; Cammi, R.; Pomelli, C.; Ochterski, J. W.; Ayala, P. Y.; Morokuma, K.; Voth, G. A.; Salvador, P.; Dannenberg, J. J.; Zakrzewski, V. G.; Dapprich, S.; Daniels, A. D.; Strain, M. C.; Farkas, O.; Malick, D. K.; Rabuck, A. D.; Raghavachari, K.; Foresman, J. B.; Ortiz, J. V.; Cui, Q.; Baboul, A. G.; Clifford, S.; Cioslowski, J.; Stefanov, B. B.; Liu, G.; Liashenko, A.; Piskorz, P.; Komaromi, I.; Martin, R. L.; Fox, D. J.; Keith, T.; Al-Laham, M. A.; Peng, C. Y.; Nanayakkara, A.; Challacombe, M.; Gill, P. M. W.; Johnson, B.; Chen, W.; Wong, M. W.; Gonzalez, C.; Pople, J. A. Gaussian 03, Revision D.01; Gaussian, Inc.: Wallingford, CT, 2004.

(17) Roy, L. E.; Hay, P. J.; Martin, R. L. J. Chem. Theory Comput. 2008, 4, 1029-1031.

(18) Klamt, A.; Schüurmann, G. J. Chem. Soc., Perkin. Trans. 1993, 2, 799-805.

(19) Andzelm, J.; Kölmel, C.; Klamt, A. J. Chem. Phys. 1995, 103, 9312-9320.

(20) Barone, V.; Cossi, M. J. Phys. Chem. A 1998, 102, 1995-2001.

(21) Cossi, M.; Gega, N.; Scalmani, G.; Barone, V. J. Comput. Chem. 2003, 24, 669-691.

(22) Siegbahn, P. E. M.; Borowski, T. Acc. Chem. Res. 2006, 39, 729-738.

(23) Himo, F. Theo. Chem. Acc. 2006, 116, 232-240.

(24) Himo, F.; Siegbahn, P. E. M. J. Biol. Inorg. Chem. 2009, 14, 643-651.

(25) Siegbahn, P. E. M.; Himo, F. Wiley Interdiscip. Rev., Comput. Mol. Sci. 2011, 1, 323-336.

(26) Huisgen, R. Angew. Chem. Chem., Int. Ed. Engl. 1963, 2, $565-632$.

(27) DePuy, C. H.; Gareyev, R.; Hankin, J.; Davico, G. E.; Krempp, M.; Damrauer, R. J. Am. Chem. Soc. 1998, 120, 5086-5092.

(28) Van Assema, S. G. A.; de Kanter, F. J. J.; Schakel, M.; Lammertsma, K. Organometallics 2006, 25, 5286-5291.

(29) Li, L.; Jiao, Y.; Brennessel, W. W.; Jones, W. D. Organometallics 2010, 29, 4593-4605.

(30) Berteloite, C.; Le Picard, S. D.; Balucani, N.; Canosa, A.; Sims, I. R. Phys. Chem. Chem. Phys. 2010, 12, 3677-3689.

(31) Ess, D. H.; Houk, K. N. J. Am. Chem. Soc. 2007, 129, 10646-10647.

(32) Ess, D. H.; Houk, K. N. J. Am. Chem. Soc. 2008, 130, 10187-10198.

(33) Amme, M. J.; Kazi, A. B.; Cundari, T. R. Int. J. Quantum Chem. 2010, 110, 1702-1711.

(34) Woon, D. E. J. Phys. Chem. A 2007, 111, 11249-11253.

(35) Zeng, X.; Davico, G. E. J. Phys. Chem. A 2003, 107, $11565-11576$
(36) Evleth, E. M.; Kassab, E.; Jessri, H.; Allavena, M.; Montero, L.; Sierra, L. R. J. Phys. Chem. 1996, 100, 11368-11374.

(37) Xie, H.-B.; Ding, Y.-H.; Sun, C.-C. THEOCHEM 2006, $776,105-112$.

(38) Siegbahn, P. E. M. J. Phys. Chem. 1996, 100, 14672-14680.

(39) Beyramabadi, S. A.; Eshtiagh-Hosseini, H.; Housaindokht, M. R.; Morsali, A. Organometallics 2008, 27, 72-79.

(40) Comas-Vives, A.; Stirling, A.; Lledós, A.; Ujaque, G. Chem.Eur. J. 2010, 16, 8738-8747.

(41) Kragten, D. D.; van Santen, R. A. J. Phys. Chem. A 1999, 103, $80-88$.

(42) Keith, J. A.; Nielsen, R. J.; Oxgaard, J.; Goddard, W. A., III. J. Am. Chem. Soc. 2007, 129, 12342-12343.

(43) Mascharak, P. K. Coord. Chem. Rev. 2002, 225, 201-214.

(44) Hopmann, K. H.; Guo, J.-D.; Himo, F. Inorg. Chem. 2007, 46, $4850-4856$.

(45) Hopmann, K. H.; Himo, F. Eur. J. Inorg. Chem. 2008, 14061412.

(46) Hopmann, K. H.; Himo, F. Eur. J. Inorg. Chem. 2008, 34523459.

(47) Jackson, A. B.; Schauer, C. K.; White, P. S.; Templeton, J. L. J. Am. Chem. Soc. 2007, 129, 10628-10629.

(48) Germain, M. E.; Temprado, M.; Castonguay, A.; Kryatova, O. P.; Rybak-Akimova, E. V.; Curley, J. J.; Mendiratta, A.; Tsai, Y.-C.; Cummins, C. C.; Prabhakar, R.; McDonough, J. E.; Hoff, C. D. J. Am. Chem. Soc. 2009, 131, 15412-15423.

(49) Achord, P.; Fujita, E.; Muckerman, J. T.; Scott, B.; Fortman, G. C.; Temprado, M.; Cai, X.; Captain, B.; Isrow, D.; Weir, J. J.; McDonough, J. E.; Hoff, C. D. Inorg. Chem. 2009, 48, 7891-7904. 